\title{
EFFECTS OF NANOCLAY CONTENTS ON THE PROPERTIES OF WATER-BASED COATING
}

\author{
Anwar UMK ${ }^{1}$ *, Alia-Syahirah $\mathbf{Y}^{2}$, Tumirah $\mathrm{K}^{1}$, Hamdan $\mathbf{H}^{1} \&$ Lee $\mathrm{SH}^{2}$ \\ ${ }^{1}$ Forest Products Division, Forest Research Institute Malaysia, 52109 Kepong, Selangor \\ ${ }^{2}$ Institute of Tropical Forestry and Forest Products, Universiti Putra Malaysia, 43400 UPM Serdang, Selangor \\ *mkanwar@frim.gov.my \\ Submitted October 2018; accepted March 2019
}

\begin{abstract}
Different loadings of nanoclay, namely 2, 4, 6, 8 and $10 \%$ were mixed into water based polyurethane by homogenisation process and were coated on rubberwood panels. Effects of the incorporation of nanoclay on the chemical, thermal properties, adhesion and mechanical properties of the wood coatings were investigated. Fourier transforms infrared analysis revealed that the polyurethane structure did not change by the addition of nanoclay. Thermogravimetric analysis showed that the coatings added with nanoclay possessed higher residual masses. Decomposition temperature of the coatings added with 2, 4 and $6 \%$ nanoclay increased, but decreased when higher loadings were used, probably attributed to the nanoclay agglomeration effect. Impact and scratch resistance of the coatings were improved by the addition of up to $6 \%$ nanoclay. On the other hand, abrasion resistance of the coatings was improved when $2 \%$ nanoclay was added but started to decrease when $4 \%$ nanoclay were used. Moreover, the addition of nanoclay slightly reduced the transparency of the water based coating. Therefore, addition of $2 \%$ nanoclay would be sufficient to obtain satisfying results as higher nanoclay content did not result in further improvement of the properties.
\end{abstract}

Keywords: Polyurethane, nanoclay, thermal stability, impact, abrasion, scratch

\section{INTRODUCTION}

Coating is primarily used for surface protection and provides a defence against chemical, mechanical and environmental threats by preventing water, oil or air penetration, chemical corrosion, UV penetration and electrical conduction. Coating is also used for decorating buildings, printing materials and various utensils. Water-based coatings (WBC) have been around for decades and have been greatly improved in recent years to meet high-quality standards worldwide (Shannon 2001). The WBC, as with other coating options, have advantages and disadvantages and possess very different properties from conventional solvent based coatings. The WBC are easy to apply and ecofriendly due to the content of water as the main solvent, together with other solvents, i.e. glycol ethers. The WBC contain no hydrocarbon solvents and therefore can be used safely. They can be formulated to offer the best combination of benefits for a particular operation.

However, along with these advantages, some drawbacks of the WBC have been identified, such as inferior hardness, poor heat resistance and low water and solvent resistance (Jhon et al. 2001). Moreover, WBC have lower chemical resistance and shorter shelf lives due to their chemical reactivity with water. Therefore, attempts have been made to enhance the mechanical properties of WBC by incorporating nanoparticles in them (Katsikis et al. 2007). Commercial filler materials are available in sizes which are associated with undesirable properties such as decrease in mechanical strength, haziness of coatings due to loading, inferior abrasion and scratch resistance. Thus, high loading of conventional filler is required to satisfy the function. Smaller and uniformly dispersed fillers are required to improve the mechanical properties of coating materials (Sonawane et al. 2010).

Nanoparticles such as nanoclay found applicability in coatings to meet mechanical requirements and improvement in thermal stability (Bertini et al. 2006). Nanoclay, a finegrained crystalline material, is an important mineral with multifarious applications that help to improve the quality of product. In comparison with other fillers, nanoclay is a 
relatively inert chemical that has a number of unique characteristics such as high interfacial area and aspect ratio, as well as the existence of an expandable gallery, making it favourable in coatings. Incorporation of nanoclay in coating films resulted in better mechanical strength such as abrasion and scratch resistance, enhanced resistance against corrosion and higher thermal stability. Researchers have reported that the addition of nanoclay provides excellent mechanical properties of nanocoatings due to its high surface area to volume ratio (Yu et al. 2006, Bhanvase et al. 2009).

Addition of nanoclay into various types of coating has been studied and reported. Montmorillonite nanoclay has been incorporated into palm oil-based polyalkyds and improved tensile properties and thermal stability (Islam et al. 2016). Morote-Martinez et al. (2011) added unmodified nanoclay into unsaturated polyester resin coating and found that the resultant coating possessed good adhesion and enhanced impact strength. Superhydrophobic coatings were successfully produced by adding silicate nanoclay particles into a sol-gel silica matrix (Subasri \& Hima 2015). Incorporation of mix clay nanoparticles improved abrasion resistance, water vapor barrier and anticorrosion properties in epoxy resin coating (Madhup et al. 2017). Thermal stability and visible transparency of waterbased polyamide-imide coating were enhanced by the addition of organo-montmorillonite nanoclay (Naderi-Samani et al. 2016). However, studies on the addition of nanoclay into WBC or polyurethane are rather limited. Therefore, the objective of this study was to determine the effects of nanoclay addition on the properties of WBC. The finishing properties (adhesion, impact, scratch and abrasion) of the WBC after addition of nanoclay have been reported by Anwar et al. (2018). Chemical composition, thermal stability and optical transparency were evaluated and highlighted in this study as complementary to the previous study of Anwar et al. (2018).

\section{MATERIALS AND METHODS}

Rubberwood, the most commonly used species by the furniture manufacturing industries in Malaysia, were used in this study. Rubberwood timber was purchased from a local company located in Selangor, Malaysia. The rubberwood timber was then cut and planed into panels.
The panels were cut into desired size and the moisture content of each panel was conditioned until $12 \%$ was achieved, prior to the application of nanocoating.

\section{Preparation of nanocoatings}

The WBC, which was waterborne polyurethane containing $30 \%$ clear finish, was purchased from a coating manufacturer. The typical characteristics of the coating are shown in Table 1. Nanoclay, surface modified, containing octadecylamine and 3-aminopropyltriethoxysilane, was used as filler in this study. The nanocoatings were prepared by dispersing $2 \%$ of nanoclay in $50 \mathrm{ml}$ of water based coating. The mixtures were homogenised for $20 \mathrm{~min}$ at 10,000 $\mathrm{rpm}$. The dispersion process was then repeated for 4, 6, 8 and $10 \%$ of nanoclay. The samples were referred as NC2, NC4, NC6, NC8 and NC10. On the hand, WBC without nanoclay were used as control for comparison purpose.

Table 1 Coating properties

\begin{tabular}{ll}
\hline Characteristic & Property \\
\hline Appearance & Translucent liquid \\
Viscosity & Approximate $30-32 \mathrm{cP}$ at $25^{\circ} \mathrm{C}$ \\
Solid content & $33 \pm 2 \%$ \\
Dilution & No requirement \\
\hline
\end{tabular}

\section{Preparation of wood samples}

The rubberwood panels were sanded with sandpaper grit 80 followed by sandpaper grit 360 along the grain to obtain a smooth surface. Panels were conditioned in a conditioning room at $22 \pm 2{ }^{\circ} \mathrm{C}$ and relative humidity of $65 \pm 5 \%$ for one week. The panels were cut based on the standard requirements of the test where the size for adhesion, impact and scratch test were $140 \mathrm{~mm} \times 80 \mathrm{~mm} \times 5 \mathrm{~mm}$ while for abrasion test was $100 \mathrm{~mm} \times 100 \mathrm{~mm} \times 5 \mathrm{~mm}$. Each panel was coated with three layers using $75 \mu \mathrm{m}$ wire bar coater. Three replicates were prepared for each test. Upon completion, the panels were stored at room temperature in the laboratory prior to evaluation. 


\section{Fourier transforms infrared analysis}

The chemical properties of nanocoatings were analysed using a Fourier Transform Infrared Spectroscopy (FTIR). Prior to FTIR analysis, the nanocoatings were spread on the glass surface and air dried. The dried nanocoating was ground and mixed with $\mathrm{KBr}$ to form pallets. Reduced absorbance values were used in order to avoid spectral differences arising from the preparation of $\mathrm{KBr}$ pellets. The $\mathrm{KBr}$ pellets were placed on the sample holder and all spectra were recorded in the range of $4000-250 \mathrm{~cm}^{-1}$.

\section{Thermogravimetric analysis}

The thermal stability of samples was characterised by using a thermogravimetric (TGA) analyser. During TGA analysis the specimens were scanned from $25-1000{ }^{\circ} \mathrm{C}$ at a rate of $5{ }^{\circ} \mathrm{C} \mathrm{min}^{-1}$ under a nitrogen gas atmosphere. A purge flow of $50.03 \mathrm{~mL} \mathrm{~min}^{-1}$ nitrogen was maintained all along the experiment. The nitrogen was purged for 10 min before starting the heating programme, to establish an inert environment. A high heating rate was implemented to obtain a no time-consuming classification procedure, and also to test the classification methodologies in the worst conditions. Mass of the specimen was around 10 to $15 \mathrm{mg}$. The thermogram recorded the percentage of weight loss versus temperature. The mass change of the sample was recorded continuously over temperature and time intervals.

\section{Adhesion test (cross-cut)}

The adhesion test on the substrate was carried out using cross-cut tape method based on BS EN ISO 2409 (BS 2013). A single blade cutter was used to make lattice pattern. The number of cuts for each lattice pattern was six, and the spacing between each cut at both directions were $2 \mathrm{~mm}$. An adhesive tape was placed over the lattice area and removed after $5 \mathrm{~min}$. The cut area percentage was examined.

\section{Impact test-resistance to mechanical damage}

The relative resistance of finishes was carried out based on BS 3962: Part 6 (BS 1980) whereby a steel ball was dropped from $2 \mathrm{~m}$ height on to the test panel. The area was examined and rated based on the assessment code stipulated in the standard.

\section{Scratch test}

The scratch test was carried out based on BS EN ISO 1518-1 (BS 2011). The finished panel was clamped onto the panel holder. A weight was placed on the stylus. The test was started with a minimum load of $1000 \mathrm{~g}$ load and was increased by $100 \mathrm{~g}$ until a maximum load of $2000 \mathrm{~g}$.

\section{Abrasion test}

The abrasion test was done on the coated rubber wood panels based on ASTM D 4060-14 (ASTM 2014). The surface of coated panels was abraded by rotating the panel under weighted abrasive wheels. Abrasion resistance was calculated as loss in weight at 2000 abrasion cycles.

\section{RESULTS AND DISCUSSION}

\section{Fourier transforms infrared analysis}

The fourier transforms infrared (FTIR) identifies the functional groups that are present in the sample. Figure 1 shows the analysis of FTIR obtained for nanoclay, WBC and mixture of WBC with nanoclay (nanocoatings). All samples presented main transmittance regions. In the spectrum of nanoclay (Figure 1a), the bands at $3125 \mathrm{~cm}^{-1}$ could be attributed to -OH stretching for silicate and water, due to presence of water molecules from moisture. According to Abdullah et al. (2015), the peak exhibited at $1053 \mathrm{~cm}^{-1}$ confirmed the Si-O-Si bonds and Si-O stretching vibration of clay. Bands located at 2924, 2842 and $1475 \mathrm{~cm}^{-1}$ are assigned to C-H vibrations of methylene groups and bands at $523 \mathrm{~cm}^{-1}$ describe the presence of Si-O-Mg (Muthu et al. 2016).

The FTIR spectra of WBC (Figure 1b) showed absorptions of the imide group at $1774 \mathrm{~cm}^{-1}$ while the amide characterisation vibrations peaks were observed at $3347 \mathrm{~cm}^{-1}$ and $1649 \mathrm{~cm}^{-1}$. The aromatic absorption was observed around $1500 \mathrm{~cm}^{-1}$. Another characteristic band included peak at around $2920 \mathrm{~cm}^{-1}$ which corresponded to the $-\mathrm{CH}_{2}$ stretching of the polyurethane (PU) structure. The FTIR spectra of nanocoating 


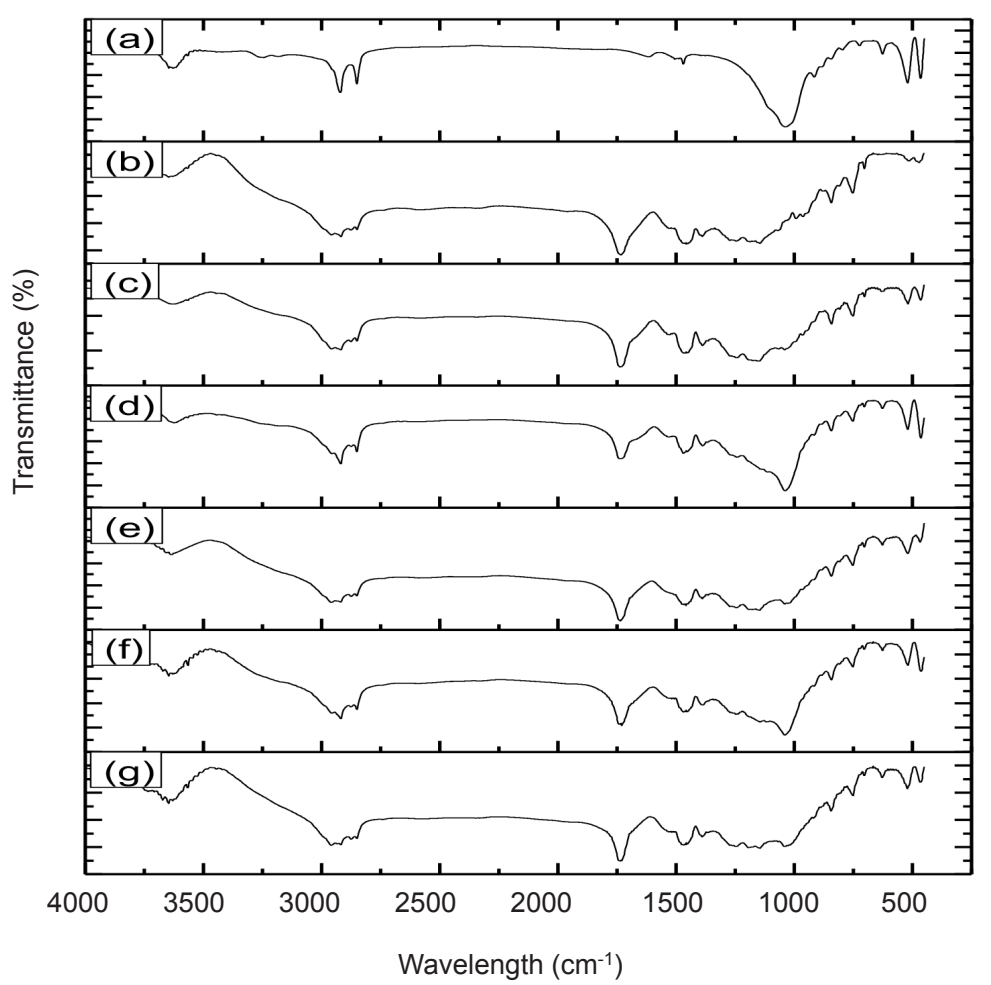

Figure 1 FTIR spectra of (a) nanoclay, (b) WBC, (c) NC 2\%, (d) NC 4\%, (e) NC 6\%, (f) NC $8 \%$ and (g) NC $10 \%$

with different percentages of nanoclay is shown in Figure 1c-1g. The figures reveal the typical characteristics bands of WBC containing nanoclay, such as amide $\mathrm{C}=\mathrm{O}$ region at around $1000 \mathrm{~cm}^{-1}$ and imide carbonyl band at $1750 \mathrm{~cm}^{-1}$. The bands around $3500 \mathrm{~cm}^{-1}$ were observed as $\mathrm{N}-\mathrm{H}$ stretching. The spectra clearly shows that no alteration bands occurred for all samples, indicating that the chemical structure of WBC does not alter by the addition of nanoclay (Hu et al. 2007, Mallakpour \& Dinari 2013).

\section{Thermogravimetric analysis}

Thermogravimetric analysis (TGA) was conducted on WBC, nanoclay and nanocoatings with different percentages of nanoclay under nitrogen atmosphere, as shown in Figure 2. It can be observed from Figure 2 that the nanoclay showed weight loss of around $35 \%$ at around $250-450{ }^{\circ} \mathrm{C}$, mainly due to degradation of organic modifier, present in the clay. No further weight decrease was observed until $700{ }^{\circ} \mathrm{C}$ indicating the thermal stability of nanoclay at high temperature. From Figure 2, it can be observed that there are two stages of thermal degradation for all samples, at around 300 and $400{ }^{\circ} \mathrm{C}$. Petrovic et al. (1994) reported that the first stages of degradation are contributed by the decomposition of hard segment of the thermally labile urethane groups. Meanwhile, the second degradation corresponds to the decomposition of soft segment.

The weight loss of nanocoatings were around $70-85 \%$ at $300-450{ }^{\circ} \mathrm{C}$. This weight loss was due to the interaction between nanoclay layers and coating. Commonly, addition of nanoclay can enhance the thermal stability of a polymer, owing to its reduced permeability as the nanoclay acts as a barrier to inhibit or delay the release of volatile degradation products (Berta et al. 2006). The nanoclay layers act as superior insulation and mass transport barrier to the volatile products generated during decomposition. This enhances the overall thermal stability of the system, as well as assists in the formation of char after thermal decomposition. The strong interfacial interaction restricts mobility of polymer chain and hinders their scission (Pan et al. 2011). The high temperature indicated the high thermal stability of WBC.

The TGA curve indicated that most weight loss of WBC was in the range of $250-450{ }^{\circ} \mathrm{C}$ due to the degradation of organic material. Higher residue masses were observed in the nanoclayadded WBC compared with that of neat WBC due to the presence of involatile inorganic clay. 


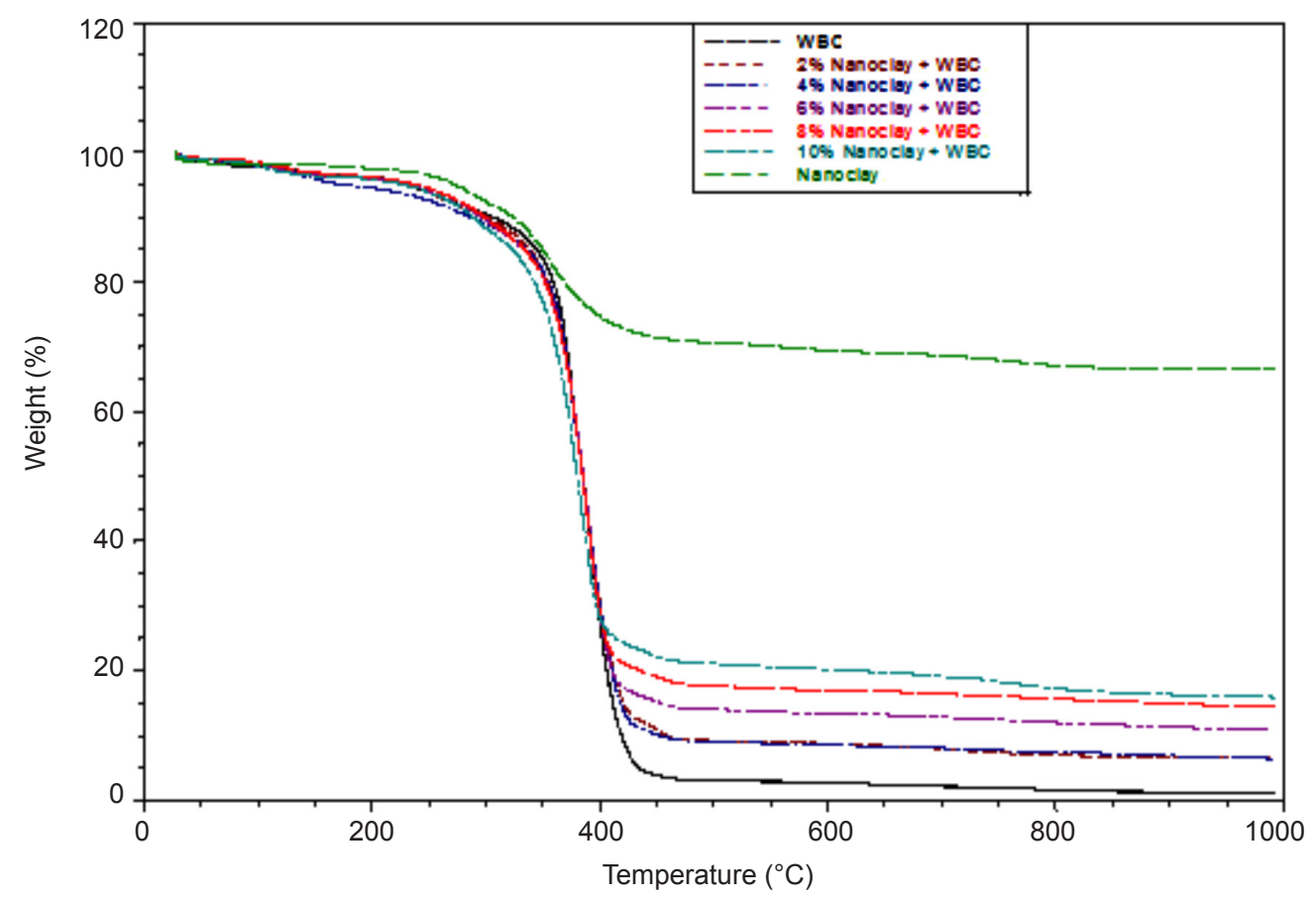

Figure 2 TGA curves of nanoclay, water based coating and nanocoatings

The residue masses increased as a function of increasing nanoclay content. Incorporation of nanoclay increased, although not significantly, the decomposition temperature of the polymers. The same results were also reported by Nam et al. (2015). At mass loss of 50\%, the thermograms of nanocoatings (NC2, NC4 and NC6) exhibited higher degradation temperature than that of WBC, suggesting that thermal stability of the coating improved with addition of up to $6 \%$ nanoclay. Nevertheless, as clay content increased, the degradation temperature of NC8 and NC10 decreased, as shown in Figure 2. Tomic et al. (2014) attributed this observation to the high agglomeration degree of incorporated clay that is responsible for the reduced thermal stability, as the curing of WBC was interfered. Increment in nanoclay loadings resulted in the reduction of intergallery spacing (d-spacing) and subsequently led to clay agglomeration (Adinoyi et al. 2011).

\section{Finishing properties of nanocoating}

Table 2 summarises the coating adhesion and mechanical properties of the neat WBC and coating with addition of different nanoclay loadings. Coating adhesion was evaluated in terms of the force at which the coating layers detach from the substrate surface or serious destruction occurs for the coat layer. High quality of adhesion to rubberwood was observed, as no detectable failure was observed for neat WBC. Same observation was obtained for the nanocoatings with 2, 4 and 6\% nanoclay content, indicating satisfied coating adhesion. Therefore, it can be concluded that the coating layer resided all along the indentation groove without any detachment or destruction (rate 0 ). Nevertheless, slight detachment (rate 1) was detected in nanocoatings with 8 and $10 \%$ nanoclay content, suggesting relatively poor adhesion quality. The inferior adhesion performance in the samples with higher loadings of nanoclay may be related to the nanoclay-induced roughness effect (Mohamadpour et al. 2011). Addition of nanoclay increased the roughness of the coatings. As a result, the contact area between the coating and rubberwood decreased due to increasing roughness and subsequently led to poorer adhesion performance.

For impact test, the results revealed a significant increase in resistance to mechanical damage (rate 3) for NC2, NC4 and NC6. However, at higher percent of nanoclay (NC8 and NC10), the impact strength decreased (rate 2). It can be concluded that the coating flexibility improved after the addition of nanoclay up to $6 \%$. Beyond this percentage, the impact strength decreased. Improvement in impact strength at lower percentage of nonclay has been reported 
Table 2 Adhesion and mechanical properties of nanocoating

\begin{tabular}{lcccc}
\hline & Adhesion & Impact & Scratch $(\mathrm{N})$ & Abrasion $(\mathrm{mg})$ at 2000 cycles \\
\hline Control & 0 & 2 & 19.70 & 274 \\
NC $2 \%$ & 0 & 3 & 19.70 & 241 \\
NC $4 \%$ & 0 & 3 & 19.70 & 290 \\
NC $6 \%$ & 0 & 3 & 19.70 & 294 \\
NC $8 \%$ & 1 & 2 & 19.70 & 396 \\
NC $10 \%$ & 1 & 2 & 19.70 & 561 \\
\hline
\end{tabular}

Adhesion: $0=$ none of the lattice is detached, $1=$ detachement is $<5 \%$; impact: $2=$ slight flaking, $3=$ moderate cracking; reproduced from Anwar et al. (2018)

before (Svoboda et al. 2002). However, at higher percentage, the drop in impact strength has not been addressed.

The scratch test results revealed that all coating samples were able to resist a maximum load of $19.7 \mathrm{~N}$, suggesting that scratch resistance was independent to nanoclay content. However, Figure 3 reveals different penetration depths resulted from the scratch test. There was a significant increase in penetration depth in NC10 sample compared with control and NC2. Figure $3 \mathrm{~b}$ shows that the scratch resistance of NC2 sample increased as the penetration depth was smaller than control (Figure 3a). The finding was in agreement with El-Fattah et al. (2015) where the scratch hardness of the polyurethane coating increased up to $4 \%$ nanoclay. Nevertheless, as the clay content increased, the scratch resistance decreased, as shown in Figure 3c, where deeper penetration was observed. Higher nanoclay content results in a softer surface of the coatings due to interference of crosslinking reaction between polymer chains of the polymer clay nanomaterials (El-Fattah et al. 2015).

Abrasion resistance test of the coatings was carried out where the weight loss was recorded after 2000 cycles. The results revealed that, compared with control sample, addition of $2 \%$ nanoclay in the coating improved its abrasion resistance with slight decrease in weight loss from $274 \mathrm{mg}$ to $241 \mathrm{mg}$. Nevertheless, the abrasion resistance of the coatings started to decrease as the loading of nanoclay increased (4\% upward), with gradual increase in weight loss from $241 \mathrm{mg}$ to $571 \mathrm{mg}$. Madhup et al. (2017) attributed such findings to the incompatibility between clay nanoparticles and coating matrix which resulted in weaker interfacial bonding. Figure 4 shows the effect of abrasion test on the rubberwood panel as control and nanocoating after 2000 cycles. However, despite the increasing weight loss recorded due to abrasion test, there was no significant effect observed on the appearance of rubber wood coated with different coatings.

\section{Optical transparency}

The addition of nanoclay reduced the transparency of the WBC, as shown in Figure 5 . The NC2 samples were slightly affected by the presence of the nanoclay but still retained its transparency. The possibility for nanoclay to interact with light is very low as the nanoparticles have dimensions smaller than the wavelength of visible light. Therefore, when used in low loadings and well dispersed into the polymer matrix, the transparency of the coating is unlikely to be significantly impaired (Frigione \& Lettieri 2018). Nevertheless, the coatings became opaquer as the amount of nanoclay increased. It can be observed from Figure $5 f$ that the transparency was significantly reduced and the coating became opaque. The changes in colour is mainly due to the colour of the nanoclay itself which has a semi-transparent or translucent appearance and the increment in opacity may be due to the agglomeration of nanoclay (Wang et al. 1996, Murima et al. 2016). Increment in nanoclay loadings in the coating could undoubtedly reduce the degree of transmittance of light through the coating film, as the light is scattered by the possibly aggregated nanoclay particles $(\mathrm{Yu}$ et al. 2003, Landry et al. 2010). 

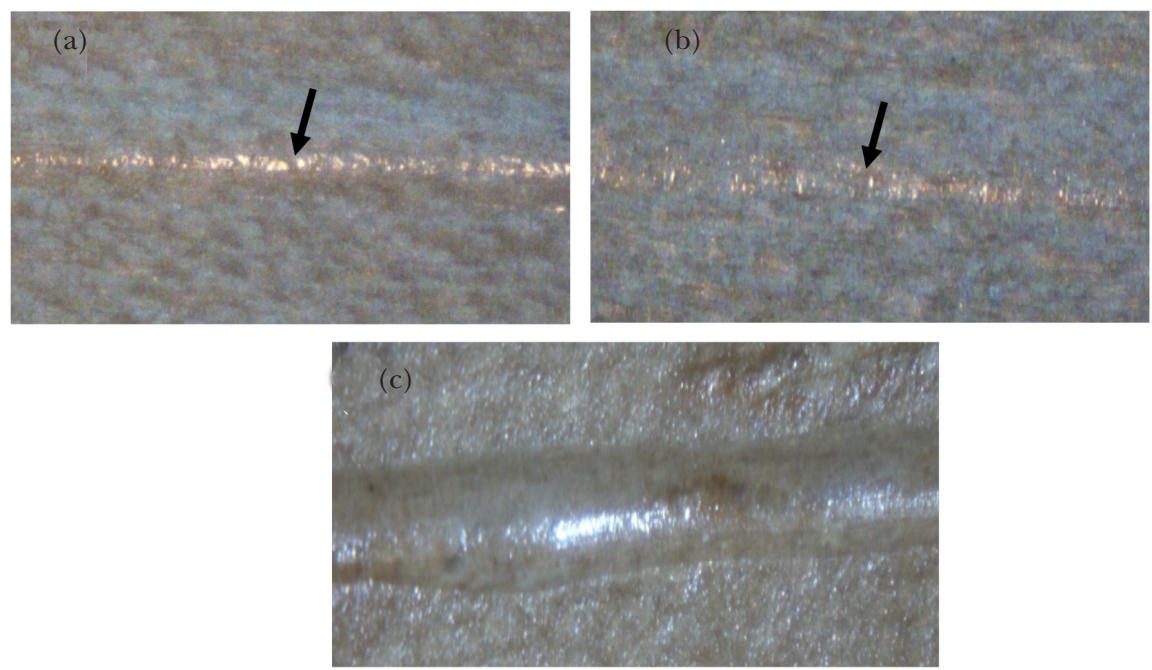

Figure 3 Penetration depth of scratch on (a) control, (b) NC 2\% and (c) NC 10\% under 18 x magnification; (a) and (c) reproduced frin Anwar et al. (2018)
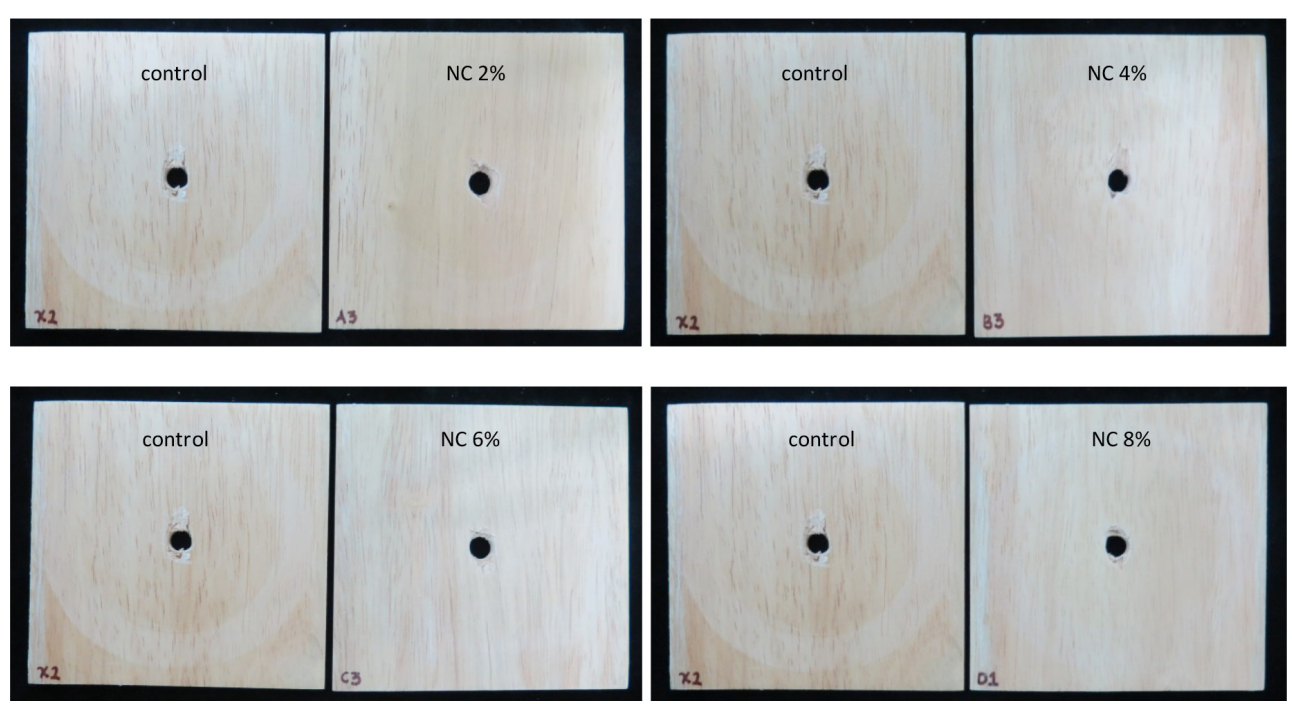

Figure 4 Abrasion test results of control and nanocoatings

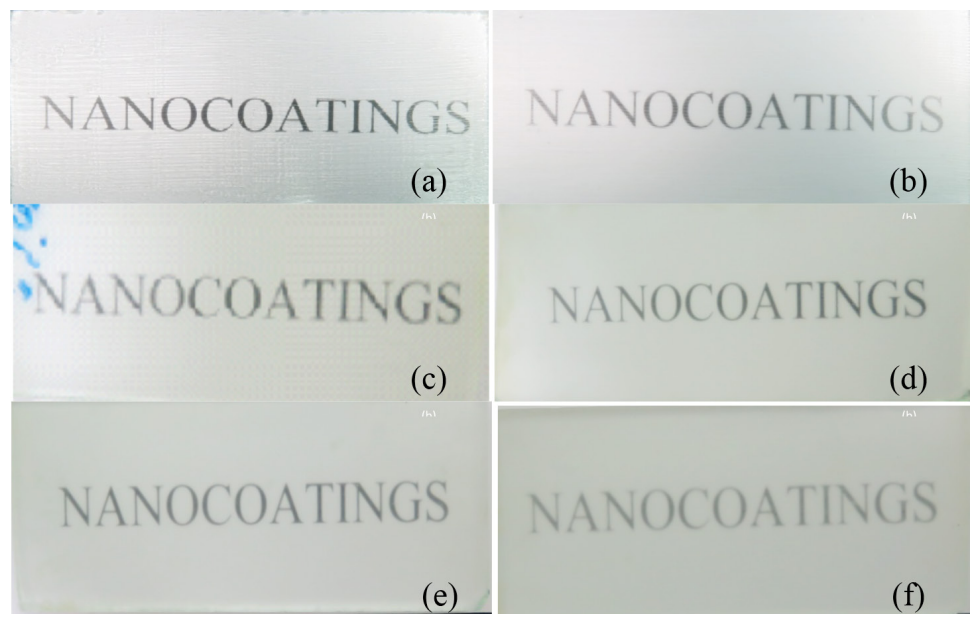

Figure 5 Opacity level of (a) control, (b) NC 2\%, (c) NC 4\%, (d) NC 6\%, (e) NC $8 \%$ and (f) NG $10 \%$ coated on glass substrates 


\section{CONCLUSIONS}

From the results obtained in the present study, it can be concluded that the addition of nanoclay into WBC resulted in an increase in adhesion and mechanical properties. The optimum percentage of nanoclay added into WBC was found to be $2 \%$, where higher nanoclay content did not result in further improvement in properties but some adverse effects were detected. The FTIR spectra confirmed the formation of nanocoating by showing the existing bands and elements in the nanoclay and WBC, respectively. Thermal stability estimated by TGA measurements showed that the thermal stability of nanocoating, with addition of up to $6 \%$ nanoclay, was reduced at low temperature but increased at high temperature, compared with pure WBC. Furthermore, the opacity of coated glass increased when the percentage of nanoclay content increased.

\section{REFERENGES}

Abdullah M, Afzaal M, Ismail Z, Ahmad A, Nazir M \& Bhat A 2015. Comparative study on structural modification of Ceiba pentandra for oil sorption and palm oil mill effluent treatment. Desalination and Water Treatment 54: 3044-3053.

Adinoy MJ, Merah N, Gasem Z \& Al-Aqeeli N. 2011. Effect of sonication time and clay loading on nanoclay dispersion and thermal property of epoxy-clay nanocomposite. Key Engineering Materials 471-472: 490-495.

Anwar UMK, Alia SY, Tumirah K, Hamdan H \& Paridah MT. 2018. Properties of water-borne coating incorporate with nanoclay. IOP Conference Series: Materials Science and Engineering 368: 012026. doi:10.1088/1757899X/368/1/012026.

Astm D 4060-14. 2014. Standard Test Method for Abrasion Resistance of Organic Coatings by the Taber Abraser. ASTM International, West Conshohocken.

Berta M, Lindsay C, Pans G \& Camino G. 2006. Effect of chemical structure on combustion and thermal behavior of polyurethane elastomer layered silicate nanocomposites. Polymer Degradation and Stability 91: 1179-1191.

Bertini F, Canetti M, Audisio G, Costa G \& Falqui L. 2006. Characterization and thermal degradation of polypropylene-montmorillonite nanocomposites. Polymer Degradation and Stability 91: 600-605.

Bhanvase BA, Gumfekar SP \& Sonawane SH. 2009. Water based PMMA-nano $\mathrm{CaCO}_{3}$ nanocomposite by in-situ polymerization technique: synthesis, characterization and mechanical properties. Polymer-Plastics Technology and Engineering 48: 939-944.

BS. 1980. BS 3962: Part 6. Finishes for Wooden FurnitureAssessment of Surface to Mechanical Damage. BSI Standard Limited. London.
BS. 2011. BS EN ISO 1518-1. Paints and Varnishes. Determination of Scratch Resistance. Constant-Loading Method. BSI Standard Limited, London.

BS. 2013. BS EN ISO 2409. Paints and Varnishes - Cross-Cut Test. BSI Standard Limited, London.

El-Fattah MA, El SAeEd AM, Dardir MM \& El-Sockary MA. 2015. Studying the effect of organo-modified nanoclay loading on thethermal stability, flame retardant, anti-corrosive and mechanicalproperties of polyurethane nanocomposite for surface coating. Progress in Organic Coatings 89: 212-219.

Frigione M \& LetTiERI M. 2018. Novel attribute of organicinorganic hybrid coatings for protection and preservation of materials (stone and wood) belonging to cultural heritage. Coatings 8: 319.

Hu Z, Li S \& Zhang C. 2007. Synthesis and properties of polyamide-imides containing fluorenyl cardo structure. Journal of Apply Polymer Science 106: 2494-2501.

Islam MR, Beg MDH \& Jamari SS. 2016. Dispersion of montmorillonite nanoclays and their effects on the thermomechanical, structural and drying properties of palm oil based coating. Progress in Organic Coatings 91: 17-24.

Jhon YK, CheOng IW \& Kim JH. 2001. Chain extension study of aqueous polyurethane dispersions. Colloids and Surfaces A: Physicochemical and Engineering Aspects 179: 71-78.

Katsikis N, Zahradnik F, Helmschrott A, Munstedt H \& Vital A. 2007 . Thermal stability of poly (methylmethacrylate)/silica nano- and microcomposites as investigated by dynamicmechanical experiments. Polymer Degradation and Stability 92: 1966-1976.

Landry V, Blanchet P, Riedl B. 2010. Mechanical and optical properties of clay-based nanocomposites coatings for wood flooring. Progress in Organic Coatings 67: 381-388.

Madhup MK, Shah NK \& ParekH NR. 2017. Investigation and improvement of abrasion resistance, water vapor barrier and anticorrosion properties of mixed clay epoxy nanocomposite coating. Progress in Organic Coatings 102: 186-193.

Mallakpour S \& Dinari M. 2013. Novel nanocomposites based on reactive organoclay of L-tyrosine and amine end-capped poly (amide-imide): synthesis and characterization. Applied Clay Science 75: 67-73.

Mohamadpour S, Pourabbas B \& Fabbri P. 2011. Anti-scratch and adhesion properties of photo-curable polymer/ clay nanocomposite coatings based on methacrylate monomers. Scientia Iranica 18: 765-771.

Morote-Martinez V, Torregrosa-CoQue R \& Martin-MartineZ JM. 2011. Addition of unmodified nanoclay to improve the performance of unsaturated polyester resin coating on natural stone. International Journal of Adhesion and Adhesives 31: 154-163.

Murima D, Pfukwa H, Tiggelman I, Hartmann PC \& Pasch H. 2016. Novel polymer clay-based nanocomposites: films with remarkable optical and water vapor barrier properties. Macromolecular Materials and Engineering 301: 836-845.

Muthu RN, Rajashabala S \& Kannan R. 2016. Synthesis, characterization of hexagonal boron nitride 
nanoparticles decorated halloysite nanoclay composite and its application as hydrogen storage medium. Renewable Energy 90: 554-564.

Naderi-Samani H, Loghman-Estarki MR, Shoja Razavi R, Ramazani M \& Jalili I. 2016. Water-based polyamide imide - nanoclay coating: preparation, characterization, thermal stability and visible transparency. Progress in Organic Coatings 101: 502-509.

NAm BU, Min KD \& Son Y. 2015. Investigation of the nanostructure thermal stability, and mechanical properties of polylactic acid/cellulose acetate butyrate/clay nanocomposites. Materials Letters 150: 118-121.

PAN LY, Zhan MS \& WANG K. 2011. High-temperature-resistant polyimide/montmorillonite nanocomposite foams by solid blending. Polymer Engineering and Science 51: 1397-1403.

Petrovic Z, Zavargo Z, Flynn JH \& Macknight WJ. 1994. Thermal degradation of segmented polyurethanes. Journal of Applied Polymer Science 51: 1087-1095.

Shannon D. 2001. Water-Borne Coatings. Jamestown Paint \& Varnish Company, Jamestown.

Sonawane SH, Teo BM, Brotchie A, Grieser F \& Ashokkumar M. 2010. Sonochemical synthesis of
$\mathrm{ZnO}$ encapsulated functional nanolatex and its anticorrosive performance. Industrial and Engineering Chemistry Research 49: 2200-2205.

SubasRi R \& Hima H. 2015. Investigations on the use of nanoclay for generation of superhydrophobic coatings. Surface and Coatings Technology 264: 121-126.

Svoboda P, Zeng C, Wang H, James L, David L \& Tomasko L. 2002. Morphology and mechanical properties of polypropylene/organoclay nanocomposites. Journal of Applied Polymer Science 85: 1562-1570.

Tomic MD, Dunjic B, Likic V, Bajat J, Rogan J \& Djonlagic J. 2014. The use of nanoclay in preparation of epoxy anticorrosive coatings. Progress in Organic Coatings 77: 518-527.

Wang Z, Lan T \& Pinnavaia TJ. 1996. Hybrid organicinorganic nanocomposites formed from an epoxy polymer and a layered silicic acid (magadiite). Chemistry of Materials 8: 2200-2204.

Yu YH, Lin CY, Yeh JM \& Lin WH. 2003. Preparation and properties of poly(vinyl alcohol)-clay nanocomposite materials. Polymer 44: 3553-3560.

Yu H, Wang L, Shi Q, Jiang S \& Jiang G. 2006. Preparation of epoxy resin $/ \mathrm{CaCO}_{3}$ nanocomposites and performance of resultant powder coatings. Journal of Applied Polymer Science 10: 2656-2660. 